\title{
Granulomatous Arteritis
}

National Cancer Institute

\section{Source}

National Cancer Institute. Granulomatous Arteritis. NCI Thesaurus. Code C34653.

Inflammation of the arteries that is characterized by the presence of granulomas. 